\title{
Rheological Behavior of Nanosilica Suspensions in Poly(Ethylene Oxide) Solutions with Sodium Chloride
}

\author{
Yuji Hirose \\ Department of Urban Environment Systems, Graduate School of Engineering, Chiba University, Chiba, Japan \\ Email:hirose@tu.chiba-u.ac.jp
}

How to cite this paper: Hirose, Y. (2017) Rheological Behavior of Nanosilica Suspensions in Poly(Ethylene Oxide) Solutions with Sodium Chloride. Materials Sciences and Applications, 8, 333-341.

https://doi.org/10.4236/msa.2017.85022

Received: February 30, 2017

Accepted: May 12, 2017

Published: May 15, 2017

Copyright $\odot 2017$ by author and Scientific Research Publishing Inc. This work is licensed under the Creative Commons Attribution International License (CC BY 4.0).

http://creativecommons.org/licenses/by/4.0/

\section{(c) (7) Open Access}

\begin{abstract}
Suspensions of silica nanoparticles showed shear-thickening profiles under steady shear conditions up on addition of a small amount of poly(ethylene oxide) (PEO). The suspensions turned into gels upon shaking and their fluidity was recovered several minutes after resting. We studied the rheological properties of these shake gels with small amounts of sodium chloride $(\mathrm{NaCl})$. Gelation occurred at lower shear rates upon addition of small amounts of $\mathrm{NaCl}$. In addition, the time taken by the gelated samples to recover their original viscosity increased with the increasing $\mathrm{NaCl}$ content. The weakened repulsive interactions between the silica particles upon $\mathrm{NaCl}$ addition lead to particles in closer proximity, and three-dimensional networks of PEO chains are easily formed as the electric double layer of the particles becomes thinner.
\end{abstract}

\section{Keywords}

Suspension, Nanoparticles, Shake Gel, Sol-Gel Transition, Electric Double Layer

\section{Introduction}

When considering suspensions of fine particles in polymer solutions, the polymer chains can adsorb to different particles, binding them together and creating polymer bridges [1] [2] [3] [4]. In order to bridge large particles, several polymer chains must attach to the surface of the particles. In this scenario, each polymer molecule binds the particles at multiple positions of the chain and it is hard to break all those points of attachments imultaneously. Therefore, polymer bridging is considered irreversible. On the other hand, for small particles of diameter $<30 \mathrm{~nm}$, only a few points are required to bind the particles [5] [6] [7], and the polymer bridges can be broken by thermal motion, leading to reversible bridging 
[8] [9]. Such colloidal particle/polymer mixtures are commonly applied in industrial and environmental fields [10] [11] [12] [13].

Poly(ethylene oxide) (PEO) is a well-known water-soluble polymer. PEO has many ether oxygen atoms in the main chain and, upon contact with silica, hydrogen-bonds with the silanol groups are formed [9]. When a small amount of PEO is dissolved in a silica particle suspension, adsorption of the polymer on the particles influences its rheological properties. For example, such a suspension would show shear-thickening behavior under steady shear flow. Specifically, discontinuous viscosity jumps are observed at certain shear rates, and the suspensions turn into gels after shaking [14]. It is believed that gelation occurs due to elasticity of the polymer chains between each two points of attachment on the surface of the particles [15]. Furthermore, such gelated suspensions recover their original fluidity under quiescent conditions [9] [14]. The temporary networks created under shear flow collapse after thermal motion treatments under these conditions. Therefore, nanoparticle suspensions with polymers show sol-gel transitions controlled by shaking or flow-speed conditions [14]. It is considered that the number of silica particles attached to each polymer chain increases and temporary 3Dnetwork structures are created by shaking the suspensions [9]. This phenomenon has been observed for clay nanoparticles (laponite) suspended in PEO aqueous solutions [16].

In this study, we added small amounts of sodium chloride to nanosilica suspensions containing PEO and measured the rheological properties of the resulting mixtures. From the Derjaguin-Landau-Verwey-Overbeek (DLVO) theory [17] [18] [19] which explains the dispersion stability of aqueous suspensions, the electric double layer interactions between particles are weakened upon salt addition and the dispersion stability of suspensions is also weakened. It is expected that small amounts of salts influence the polymer chain network structures and the rheological properties of nanosilica suspensions with PEO. We compared the rheological properties of samples with PEO of different molecular weight and studied the influence of the polymer chain length. In addition, we evaluated the time dependence of the viscosity of gelated samples at low shear rates and determined the time taken by the fluidity to return to its original value.

\section{Materials and Methods}

\subsection{Materials}

We used colloidal silica suspensions (Cataloid SI-30, Catalyst \& Chemicals Ind. Co., Ltd. (Japan), silica 30wt\%). The diameter of the spherical particles was 11 $\mathrm{nm}$. Sodium chloride $(\mathrm{NaCl})$ and poly(ethylene oxide) (PEO) samples of molecular weight 500,000 and 2,000,000 were obtained from Wako Pure Chemical industries, Ltd. (Japan). APEO sample of molecular weight $M=200,000$ was provided by Polysciences Inc. (U.S.). When we added $\mathrm{NaCl}$ crystals to the colloidal silica suspensions directly, the silica particles aggregated drastically and $\mathrm{NaCl}$ could not be dissolved in the suspensions. Therefore, we first dissolved $\mathrm{NaCl}$ and $\mathrm{PEO}$ in water (about $10 \mathrm{~g}$ ) and then, colloidal silica and rest of water 
were added gradually. The weight fraction of silica nanoparticles in all the samples used in this study was $15 \mathrm{wt} \%$. Before rheological analysis, the samples were mixed at $40 \mathrm{rpm}$ for at least $24 \mathrm{~h}$ on a rolling device (mix rotor VMR-5R, AS ONE Co., Japan).

\subsection{Methods}

For the rheological measurements, we used a rheometer (Haake, RheoStress RS75) with double cylinder geometry with 20 and $22 \mathrm{~mm}$ diameter cylinders. The temperature was set to $298 \mathrm{~K}$ and the shear rate was varied from 1.0 to 631 $\mathrm{s}^{-1}$. Once the viscosity of the sample had increased at a low shear rate, the sample was injected in the rheometer, the cup was covered with aluminum foil, and the sample was left until the viscosity decreased (about $1 \mathrm{~h}$ ).

In order to measure the time taken by the viscosity of the shaken sample to return to its original value, the shear rate of the rheometer was set to $631 \mathrm{~s}^{-1}$ and kept at that rate for $1 \mathrm{~min}$. The shear stress was then set to $1.0 \mathrm{~Pa}$ and the shear rate was measured.

\section{Results and Discussion}

\subsection{Effect of Sodium Chloride}

Figure 1 shows the viscosity dependence on the shear rate for nanosilica suspensions in $0.5 \mathrm{wt} \%$ PEO (average molecular weight: $M=500,000$ ) solutions at different $\mathrm{NaCl}$ concentrations. Viscosity jumps and gelation were not observed at $\mathrm{NaCl}$ concentrations of 0 and $0.10 \mathrm{wt} \%$. The samples with $0.15 \mathrm{wt} \%-0.30 \mathrm{wt} \%$ $\mathrm{NaCl}$ showed shear-thickening behavior and the shear rate at the viscosity jump points decreased with the increasing $\mathrm{NaCl}$ concentration. When the $\mathrm{NaCl}$ concentration was $0.40 \mathrm{wt} \%$, the sample showed shear-thinning. In conclusion, as the ionic strength increases, the electric double layers become thinner and the repulsive interactions between the particles become weaker. When the suspensions are shaken, the particles are able to get closer, easily forming network structures.

On the other hand, the values after the viscosity jumps (at high shear rates) were found not to depend on the $\mathrm{NaCl}$ content $(0.15 \mathrm{wt} \%-0.30 \mathrm{wt} \%)$. The shear stress (about $100 \mathrm{~Pa}$ ) was also independent of the shear rate and $\mathrm{NaCl}$ content. This phenomenon indicates that no big differences exist among the network structures of PEO and silica after gelation of samples containing varying amounts of $\mathrm{NaCl}$, which suggests that similar distributions of silica particles are obtained under fast shear flow conditions regardless of the percentage of $\mathrm{NaCl}$ and the strength of the repulsive interactions between particles.

\subsection{Effect of Molecular Weight of PEO}

The viscosity curves for suspensions with PEO $(M=200,000)$ and varying amounts of $\mathrm{NaCl}$ are shown in Figure 2. The samples with $\leq 0.30 \mathrm{wt} \% \mathrm{NaCl}$ exhibited Newtonian profiles. In the case of the $0.50 \mathrm{wt} \% \mathrm{NaCl}$ sample, shear-thining be- 
havior was observed at as hear rate of $10 \mathrm{~s}^{-1}$, but the maximum viscosity value was $\sim 0.50 \mathrm{~Pa}$ s. This value is much smaller than that of the suspension with heavier PEO $(M=500,000)$ and $0.30 \mathrm{wt} \% \mathrm{NaCl}\left(5.4 \mathrm{Pas}\right.$ at $\left.20 \mathrm{~s}^{-1}\right)$. The strength of the gel decreased and gelation did not occur until more $\mathrm{NaCl}$ was added.

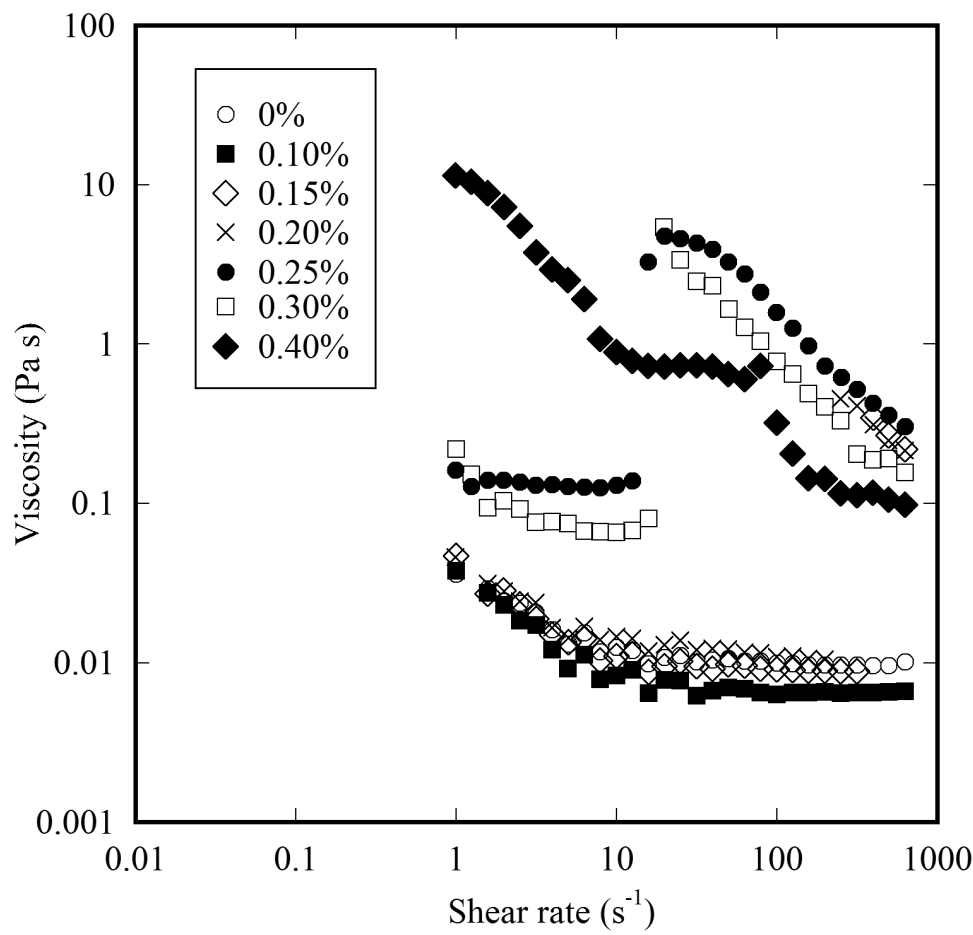

Figure 1. Viscosity dependence on the shear rate for silica nanoparticle $(11 \mathrm{~nm}$, $15 \mathrm{wt} \%)$ suspensions with PEO of average molecular weight 500,000 (0.50wt\%) and varying amounts of sodium chloride.

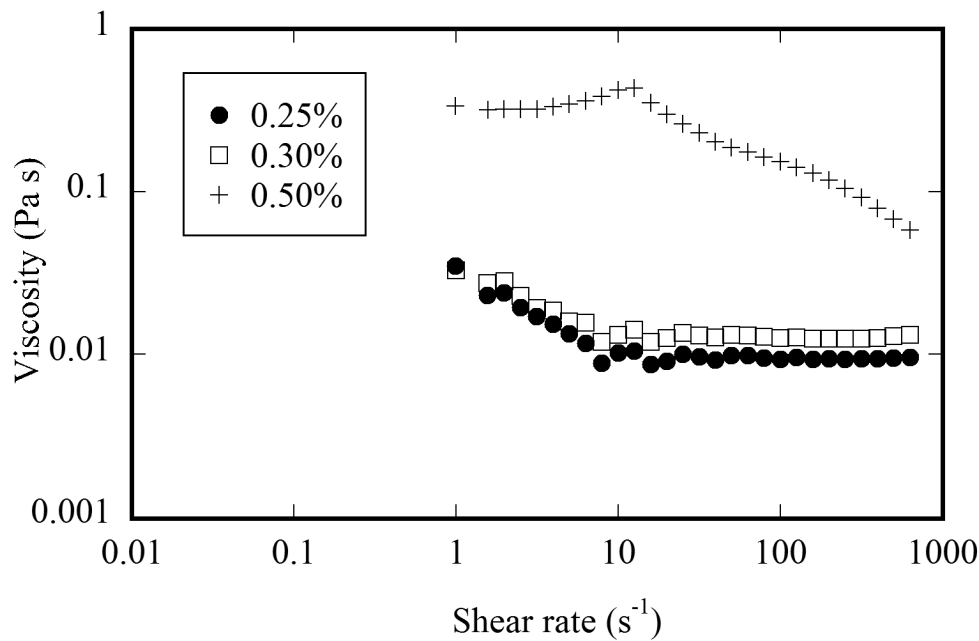

Figure 2. Viscositydependence onthe shear rate for silica nanoparticle $(11 \mathrm{~nm}$, $15 \mathrm{wt} \%)$ suspensions with PEO of average molecular weight 200,000 (0.50wt\%) and varying amounts of sodium chloride. 
Figure 3 shows the viscosity curves of suspensions with high molecular weight PEO $(M=2,000,000)$. A viscosity jump was observed for the suspension with no $\mathrm{NaCl}$ and also for the sample with $0.10 \mathrm{wt} \% \mathrm{NaCl}$ at low shear rates. The sample with $0.25 \mathrm{wt} \% \mathrm{NaCl}$ exhibited a shear-thinning profile. As in the case with PEO of $M=500,000$ (Figure 1), the viscosity after gelation did not depend on the $\mathrm{NaCl}$ content.

The viscosity curves of samples showing a viscosity jump at $\sim 10 \mathrm{~s}^{-1}$ are compared in Figure 4. The viscosity of the gelated sample with the heaviest PEO was higher than that of the sample with the lightest PEO. In this study, the size and number of silica particles and the total amount of PEO were constant. It can be concluded that the density of adsorption points is also independent of the molecular weight of PEO, since the oxygen atoms of the PEO main chains are adsorbed on the surface of the silica particles.

The different conformations of polymer chains on solid surfaces are classified as trains (segments directly attached to the surface), loops (segments between trains not attached to the surface), and tails (segments not attached including one polymer chain end) [9] [20] [21]. The number of end groups of each polymer chain and of segments floating in water (tails) increased with the decreasing molecular weight of PEO. Thus, it was concluded that the bridging density, strength of the gel, and its viscosity decreased.

\subsection{Time for the Recovery of The Viscosity in the Gelated Samples}

Figure 5 shows the time dependence of the shear rate of gelated samples with PEO $(M=500,000,0.50 \mathrm{wt} \%)$ and varying amounts of $\mathrm{NaCl}$ up on reducing the shear stress to $1.0 \mathrm{~Pa}$. The normalized data for the shear rate once the viscosity returned to its original value for the 0.15 and $0.20 \mathrm{wt} \% \mathrm{NaCl}$ samples are also plotted in Figure 6. Immediately after the measurements started, the shear rate

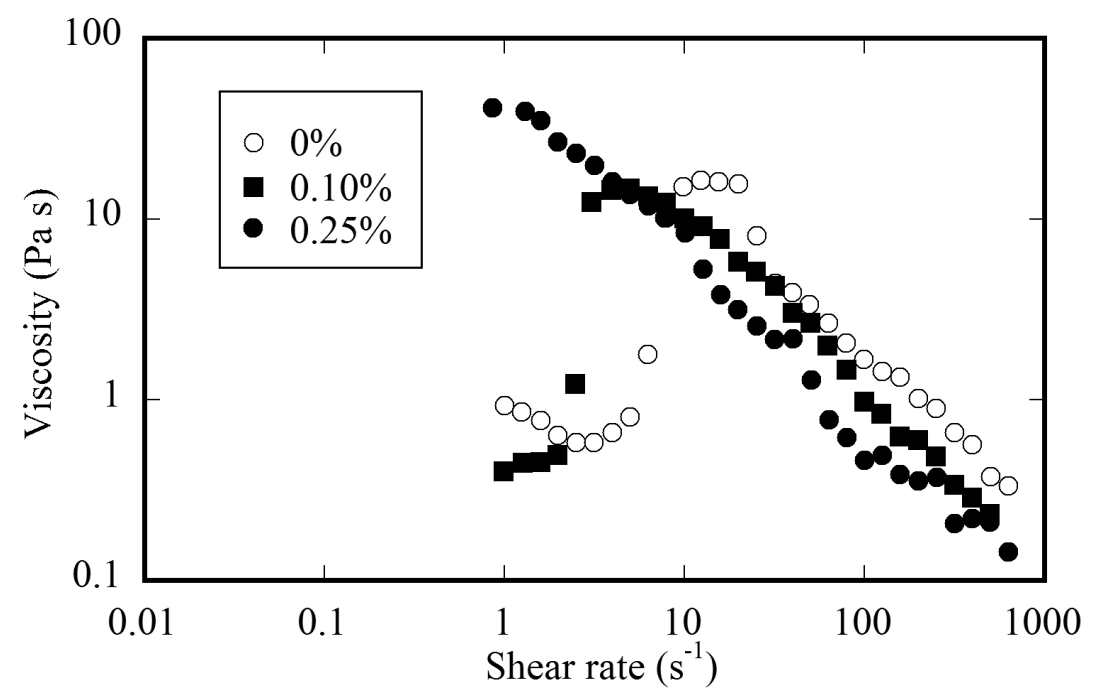

Figure 3. Viscosity dependence on the shear rate for silica nanoparticle (11 nm, 15wt\%) suspensions with PEO of average molecular weight 2,000,000 (0.50wt\%) and varying amounts of sodium chloride. 


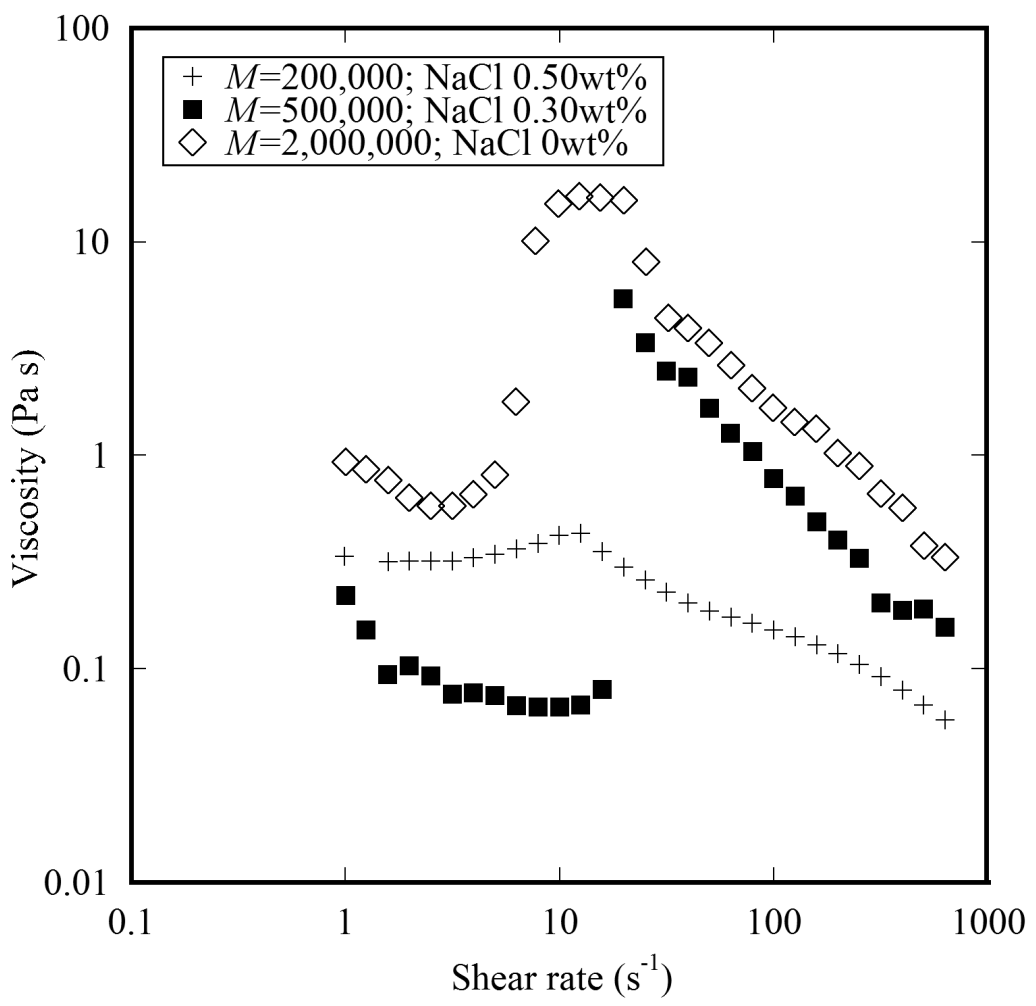

Figure 4. Viscosity dependence on the shear rate for silica nanoparticle $(11 \mathrm{~nm}, 15$ wt\%) suspensions with PEO (0.50wt\%) and sodium chloride.

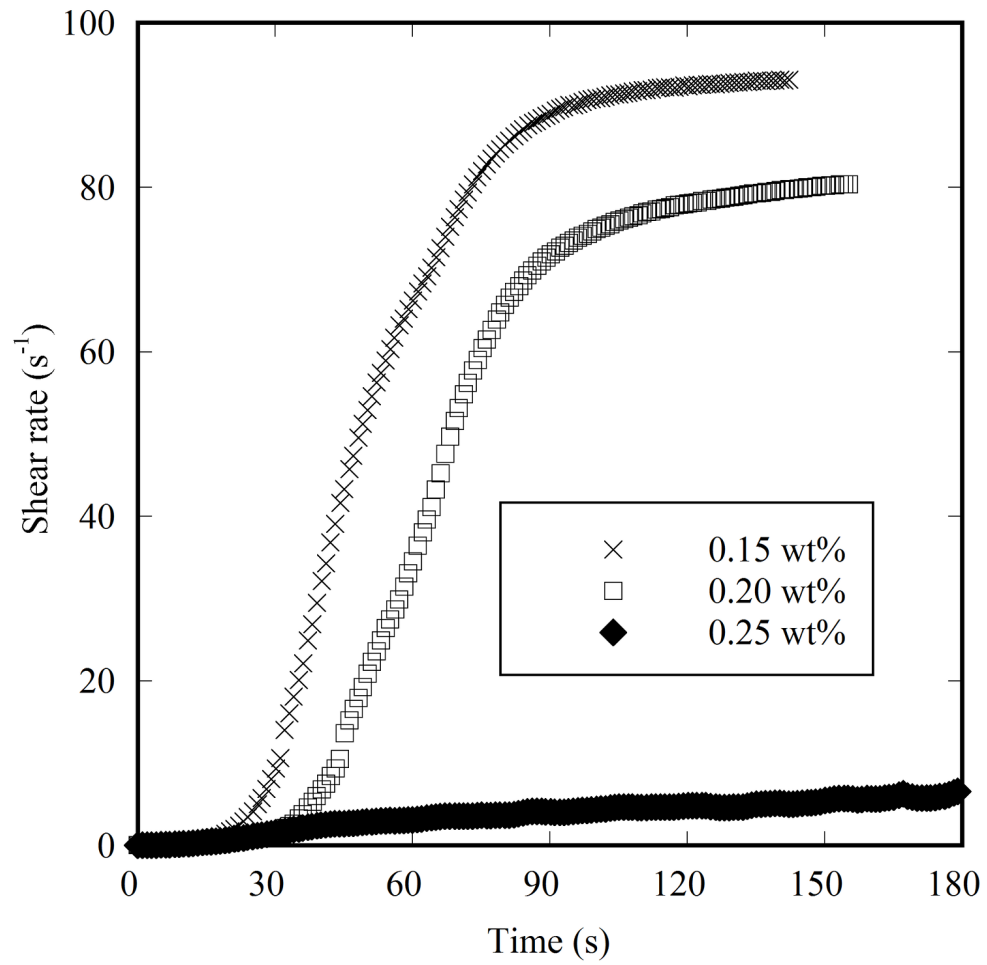

Figure 5. Time dependence of the shear rate for gelated silica nanoparticle (11 $\mathrm{nm}, 15 \mathrm{wt} \%)$ suspensions with PEO of average molecular weight 500,000 (0.50 wt\%) and varying amounts of $\mathrm{NaCl}$ under shear stress of $1.0 \mathrm{~Pa}$. 


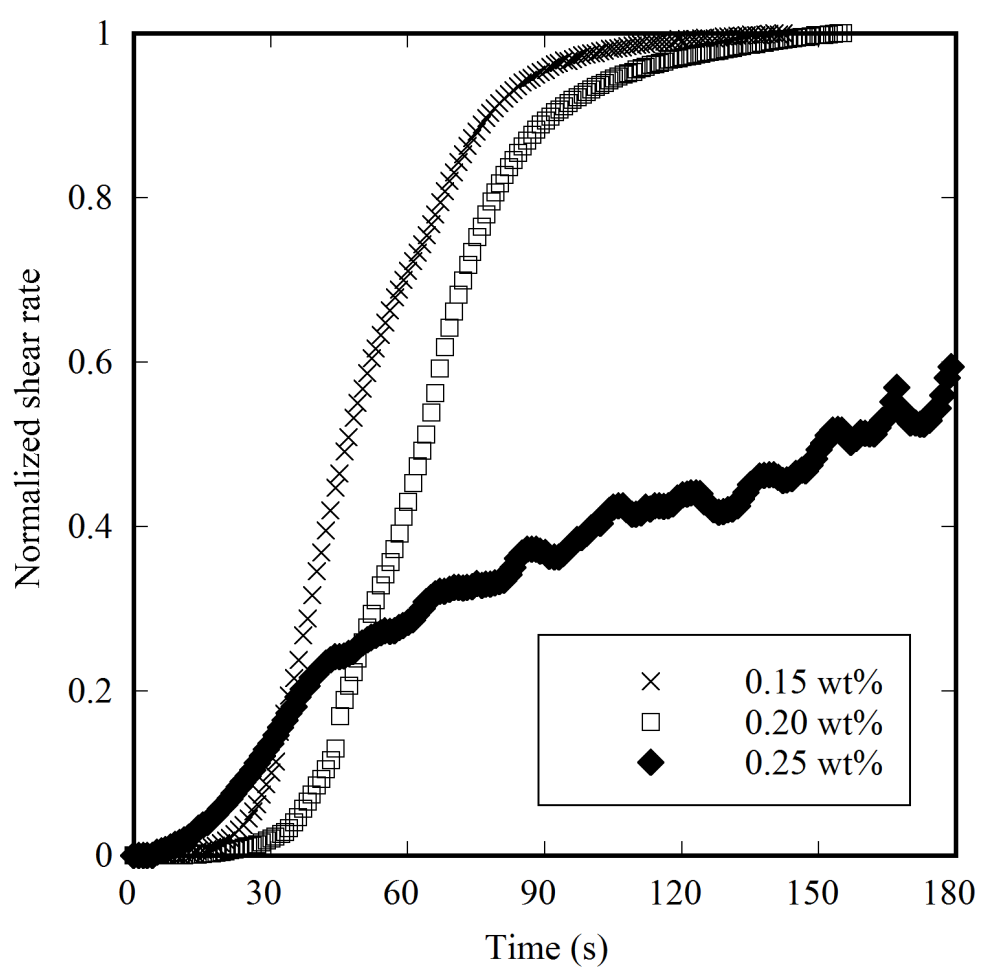

Figure 6. Normalized shear rate curves for gelated silica nanoparticle $(11 \mathrm{~nm}$, $15 \mathrm{wt} \%)$ suspensions with PEO of average molecular weight 500,000 (0.50 wt\%) and varying amounts of $\mathrm{NaCl}$ under shear stress of $1.0 \mathrm{~Pa}$.

was almost zero as the samples gelated sufficiently. The shear rate took longer to increase for suspensions with larger amounts of $\mathrm{NaCl}$. The decreased viscosity after reducing the share stress was caused by the thermal motion of the particles and polymer chains [7] [9]. From these results, it can be concluded that, when the presence of $\mathrm{NaCl}$ weakens the repulsive interactions between particles, the PEO chains cannot detach easily from the silica surface by thermal motion and longer times are required to regain the original fluidity of the gelated samples.

\section{Conclusion}

Addition of $\mathrm{NaCl}$ to silica nanoparticle/PEO aqueous shake gels results in the easy formation of networks between the silica and PEO molecules. The shear rate is reduced upon gelation due to weakening of the repulsive interactions between silica particles. The shear rate dependence of the viscosity in the gelated samples was found to be independent of the salt content, and the shear stress was about $100 \mathrm{~Pa}$ for some of the samples with silica $(11 \mathrm{~nm}, 15 \mathrm{wt} \%)$ and PEO $(M=500,000,0.50 \mathrm{wt} \%)$. It is suggested that the structure of the molecular networks in the gelated samples was not changed upon salt addition. On the other hand, increasing the molecular weight of PEO also decreased the shear rate at the viscosity jumps, although the viscosity of the gelated samples also increased. From these results, the elasticity of shake gels of nanosilica with PEO can be controlled by increasing the molecular weight of PEO or adding $\mathrm{NaCl}$. In addi- 
tion, $\mathrm{NaCl}$ addition resulted in the gelated state lasting longer. The viscoelastic behavior of gels composed of temporary networks with nanoparticles depends on the salt content and strength of the repulsive interactions between particles. It is thus concluded that, we can control the flow behavior of nanosilica suspensions with PEO and salts by controlling the salt content, polymer content, and molecular weight of polymer.

\section{Acknowledgements}

This work was supported by JSPS KAKENHI Grant Numbers JP26870098, JP16K20960.

\section{References}

[1] Somasundaran, P., Healy, T.W. and Furstenau, D.W. (1966) The Aggregation Of Colloidal Alumina Dispersions by Adsorbed Surfactant Ions. Journal of Colloid and Interface Science, 22, 599-605. https://doi.org/10.1016/0021-9797(66)90054-3

[2] Evans, R. and Napper, D.H. (1973) Flocculation of Latices by Low Molecular Weight Polymers. Nature, 246, 34-35. https://doi.org/10.1038/246034a0

[3] Fleer, G.J. and Lyklema, J. (1974) Polymer Adsorption and Its Effect on the Stability of Hydrophobic Colloids. Journal of Colloid and Interface Science, 46, 1-12. https://doi.org/10.1016/0021-9797(74)90018-6

[4] Furusawa, K., Tezuka, Y. and Watanabe, N. (1980) Adsorbed Polymer Layers on the Platelet Particles and Their Effect on Colloidal Stability. I. Effect of Polymer Concentration and Molecular Weight. Journal of Colloid and Interface Science, 73, 21-26. https://doi.org/10.1016/0021-9797(80)90116-2

[5] Iler, R.K. (1971) Relation of Particle Size of Colloidal Silica to the Amount of a Cationic Polymer Required for Flocculation and Surface Coverage. Journal of Colloid and Interface Science, 37, 364-373. https://doi.org/10.1016/0021-9797(71)90304-3

[6] Otsubo, Y. (1992) Effect of Particle Size on the Bridging Structure and Elastic Properties of Flocculated Suspensions. Journal of Colloid and Interface Science, 153, 584-586. https://doi.org/10.1016/0021-9797(92)90350-U

[7] Kamibayashi, M., Ogura, H. and Otsubo, Y. (2006) Rheological Behavior of Suspensions of Silica Nanoparticles in Associating Polymer Solutions. Industrial \& Engineering Chemical Research, 45, 6899-6905. https://doi.org/10.1021/ie0512486

[8] Otsubo, Y. and Nakane, Y. (1991) Simulation of Bridging Flocculation and Elastic Percolation in Suspensions. Langmuir, 7, 1118-1123. https://doi.org/10.1021/la00054a017

[9] Saito, Y., Hirose, Y. and Otsubo, Y. (2011) Shear-Induced Reversible Gelation of Nanoparticle Suspensions Flocculated by Poly(Ethylene Oxide). Colloids and Surfaces A: Physicochemical and Engineering Aspects, 384, 40-46.

https://doi.org/10.1016/j.colsurfa.2011.03.017

[10] Yang, W.Y., Qian, J.W. and Shen, Z.Q. (2004) A Novel Flocculant of $\mathrm{Al}(\mathrm{OH})_{3}-\mathrm{Po}-$ lyacrylamide Ionic Hybrid. Journal of Colloid and Interface Science, 273, 400-405. https://doi.org/10.1016/j.jcis.2004.02.002

[11] Goodwin, D.J., Sepassi, S., King, S.M., Holland, S.J., Martini, L.G. and Lawrence, M.J. (2013) Characterization of Polymer Adsorption onto Drug Nanoparticles Using Depletion Measurements and Small-Angle Neutron Scattering. Molecular Pharmaceutics, 10, 4146-4158. https://doi.org/10.1021/mp400138e

[12] Ye, L., Tang, Y. and Qiu, D. (2014) Enhance the Mechanical Performance of Polyacrylamide Hydrogel Byaluminium-Modified Colloidal Silica. Colloids and Surfaces A: Physicochemical and Engineering Aspects, 447, 103-110. https://doi.org/10.1016/j.colsurfa.2014.01.072 
[13] Yan, F., Ye, L. and Qiu, D. (2016) Effect of Particle/Polymer Number Ratio on the Structure and Dynamics of Complex between Large Polymer and Nanoparticle. Colloids and Surfaces A: Physicochemical and Engineering Aspects, 507, 67-75. https://doi.org/10.1016/j.colsurfa.2016.07.080

[14] Kamibayashi, M., Ogura, H. and Otsubo, Y. (2008) Shear-Thickening Flow of Nanoparticle Suspensions Flocculated by Polymer Bridging. Journal of Colloid and Interface Science, 321, 294-301. https://doi.org/10.1016/j.jcis.2008.02.022

[15] Otsubo, Y. (1994) Normal Stress Behavior of Highly Elastic Suspensions. Journal of Colloid and Interface Science, 163, 507-511. https://doi.org/10.1006/jcis.1994.1130

[16] Zebrowski, J., Prasad, V., Zhang, W., Walker, L.M. and Weitz, D.A. (2003) Effect of Particle/Polymer Number Ratio on the Structure and Dynamics of Complex between Large Polymer and Nanoparticle. Colloids and Surfaces A: Physicochemical and Engineering Aspects, 213, 189-197. https://doi.org/10.1016/S0927-7757(02)00512-5

[17] Derjaguin, B. (1939) A Theory of Interaction of Particles in Presence of Electric Double-Layers and the Stability of Lyophobe Colloids and Disperse Systems. Acta Physicochimica U.R.S.S., 10, 333-346.

[18] Derjaguin, B. and Landau, L.D. (1941) Theory of the Stability of Strongly Charged Lyophobic Sols and of the Adhesion of Strongly Charged Particles in Solutions of Electrolytes. Acta Physicochimica U.R.S.S., 14, 633-662.

[19] Verwey, E.J.W. and Overbeek, J.T.G. (1948) Theory of Stability of Lyophobic Colloids. Elsevier, Amsterdam.

[20] Charlaganov, M., Košovan, P. and Leermakers, F.A.M. (2009) New Ends to the Tale of Tails: Adsorption of Comb Polymers and the Effect on Colloidal Stability. Soft Matter, 5, 1448-1459. https://doi.org/10.1039/b816832f

[21] Ndong, R.S. and Russel, W.B. (2011) Effects of Molecular Weight and Volume Fraction on Rheological Properties of PDMS-Grafted Alumina in PDMS Melts. Journal of Rheology, 55, 331-351. https://doi.org/10.1122/1.3539999

\section{Submit or recommend next manuscript to SCIRP and we will provide best} service for you:

Accepting pre-submission inquiries through Email, Facebook, LinkedIn, Twitter, etc. A wide selection of journals (inclusive of 9 subjects, more than 200 journals)

Providing 24-hour high-quality service

User-friendly online submission system

Fair and swift peer-review system

Efficient typesetting and proofreading procedure

Display of the result of downloads and visits, as well as the number of cited articles

Maximum dissemination of your research work

Submit your manuscript at: http://papersubmission.scirp.org/

Or contact msa@scirp.org 